\title{
Performance Deterioration of Heavy-Haul Railway Bridges under Fatigue Loading Monitored by a Multisensor System
}

\author{
Zhiwu Yu, ${ }^{1,2}$ Zhi Shan ${ }^{1},{ }^{1,2}$ Ju Yuan, ${ }^{1,2}$ and Xiao $\mathrm{Li}^{1,2}$ \\ ${ }^{1}$ School of Civil Engineering, Central South University, 68 South Shaoshan Road, Changsha 410004, China \\ ${ }^{2}$ National Engineering Laboratory for High-Speed Railway Construction, Central South University, Changsha 410004, China \\ Correspondence should be addressed to Zhi Shan; zhishan@csu.edu.cn
}

Received 24 August 2017; Accepted 8 November 2017; Published 9 January 2018

Academic Editor: Yinan Zhang

Copyright (c) 2018 Zhiwu Yu et al. This is an open access article distributed under the Creative Commons Attribution License, which permits unrestricted use, distribution, and reproduction in any medium, provided the original work is properly cited.

\begin{abstract}
Heavy-haul railway bridges play an increasingly essential role in the transportation in China due to the increasing transport volume. The performance deterioration of the scale models of a typical heavy-haul railway bridge under fatigue loading is monitored in this work, based on a multisensor system including the fiber-reinforced polymer optical fiber Bragg grating and electrical resistance strain gauges, linear variable displacement transducer, and accelerometer. Specifically, by monitoring/ observing on the failure mode, fatigue life, load-midspan deflection response, material strain development, and so forth, this work develops an $S$ - $N$ model by comparing the relationship between fatigue life and rebar stress range with that between fatigue life and load level and proposes a damage evolution model considering the coupling of the stiffness degradation and inelastic deformation of specimens. It is found that the fatigue life of specimens is determined by the fatigue life of the rebar at the bottom and it may be lower than 2.0 million cycles with a 30-ton axle weight when environmental factors are taken into account. The predictions of the models agree well with experimental results. Therefore, this work furthers the understanding of the fatigue performance deterioration of the bridges by using a multisensor system.
\end{abstract}

\section{Introduction}

It is required to observe on the performance deterioration of heavy-haul railway bridges under fatigue loading due to the increasing transport volume and train axle weight of trains in China [1-3]. Specifically, the train axle weight is being increased from 23 tons to 30 tons and the transport volume is also being developed with the growing traffic requirement. Further, it may result in the serious performance deterioration of the bridges, such that the designed prestressed beam may be changed into a partially prestressed beam, the performance may be degraded in a short time, consequently, the fatigue life may be reduced obviously, and so forth.

As an essential method, the experimental investigations in the literature are generally able to be concluded in the following three aspects: the investigation on the fatigue performance deterioration of the reinforced concrete (RC) beams or strengthened RC beams [4-7], the investigation on that of the partially prestressed concrete (PC) beams [8-14], and the investigation on that of the heavy-haul railway bridges [15-17]. For example, Zhang et al. [8] observed on the partially PC beams with corroded rebars and found out that the fatigue life of the beams decreases and the rate of the stiffness degradation and the midspan deflection development grows with the corrosion ratio increasing. Additionally, the researchers conducted other investigations on the partially PC beams and drew some conclusions such that [9-14] the fatigue failure of the beams begins from the fatigue fracture of the rebar at the bottom, which determines the fatigue life of the beams and the maximum midspan deflection increased by $10 \% \sim 20 \%$ to failure than that in the initial case and so forth. Furthermore, according to the investigation on the fatigue performance deterioration of the heavy-haul railway bridges, firstly, an $S-N$ model [15] is developed considering the rebar stress range-fatigue life relationship and stress ratio (the ratio of initial stress range to stress range to failure) - and fatigue life relationship, by observing the scale model of bridges under fatigue loading. Secondly, Luo et al. [16] investigated on the variation of the midspan deflection, the stiffness, and the material strain during the fatigue life and 


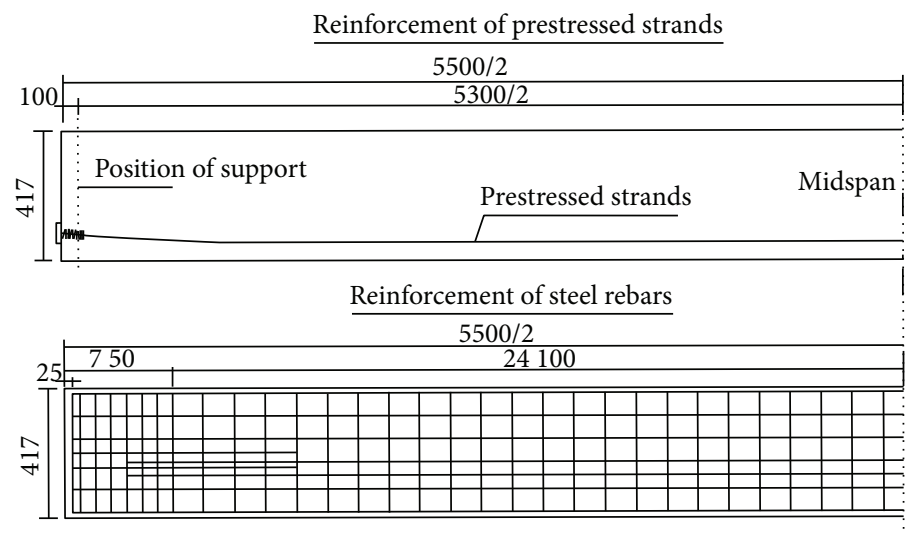

(a) Side view

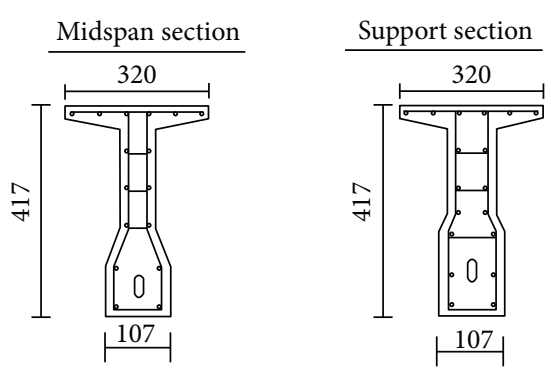

(b) Section view

FIgURE 1: Details of specimens (unit: $\mathrm{mm}$ ).

TABle 1: Parameters of specimens.

\begin{tabular}{lcccccc}
\hline Length $l(\mathrm{~mm})$ & Span $l_{0}(\mathrm{~mm})$ & Depth $h(\mathrm{~mm})$ & Web width $w(\mathrm{~mm})$ & $f_{\mathrm{cm}}(\mathrm{MPa})$ & \multicolumn{3}{c}{ Prestressed steel strand $(7 \varphi 5)$} & $f_{\mathrm{pk}}(\mathrm{MPa})$ & Bundle & Strands per bundle \\
\hline 5500 & 5300 & 417 & 80 & 53.6 & 1860 & 1 \\
\hline
\end{tabular}

developed a simplified analysis method on the variation, based on the scale model experiments; literature [15] developed a stiffness degradation model and a related damage evolution model.

However, initially, the investigation results in literature $[4-14,16]$ are generally not applicable to the performance deterioration of the heavy-haul railway bridges (i.e., PC beams), due to the different material/structural parameters or fatigue loading. For example, literature [4-7] observed on the performance deterioration of the RC beams but not PC beams, literature [8-14] focused on that of PC beams with rectangular sections $[8-10,12,14]$ or different dimension T-type sections [11, 13] compared with the typical heavy-haul railway bridges of T-type sections, and literature [16] analyzed that of unbonded PC beams rather than the bonded bridges. Additionally, for the $S-N$ model in literature [15], no explanations for the relationship between the stress ratio and the fatigue life were given, which caused approximately $20 \%$ relative errors for the resulted predictions in nearly half cases. Furthermore, the predictions of the performance deterioration models in literature [15] are not accurate enough (the relative error of $40 \%$ approximately of the predictions is higher than $20 \%$ ), and the damage evolution [15] did not consider the coupling of the stiffness degradation and the residual/inelastic deformation development, which are two essential mechanical behaviors of the bridges.

Therefore, the aim of this work is to develop a comprehensive and accurate $S-N$ model by comparing the relationship between the fatigue life and the rebar stress range with that of the fatigue life and the load level and to propose a damage evolution model considering the coupling of the stiffness degradation and inelastic deformation, by monitoring/ observing on the failure mode, the fatigue life, the load- midspan deflection response, the material strain development, and so forth, using a multisensor system. Specifically, the comparison will be conducted to analyze the influence of the key factors on the fatigue life of the bridges. With this methodology, the developed $S-N$ model is more considerable than that in literature [15-17]. Additionally, the coupling of the stiffness degradation and inelastic deformation will be taken into account to better understand the performance deterioration of the bridge and to characterize the fatigue behaviors more accurately than that in literature [15-17].

This work monitors the performance deterioration of the scale models of a typical heavy-haul railway bridge in China under fatigue loading based on a multisensor system, analyzes the results of the failure mode, the fatigue life, the load-midspan deflection response, the material strain development, and so forth, and further develops an $S-N$ model and a damage evolution model to better understand the fatigue performance deterioration of the bridge.

\section{Materials and Methods}

2.1. Specimen Details. The specimen is designed based on a typical heavy-haul railway bridge, the simply supported PC beam with T-type section and $32 \mathrm{~m}$ span, which follows the design standard of 2059F [1-3, 15]. And it satisfies the requirement of the mechanical similarity between the specimen and the standard beam. Therefore, 12 specimens (the 1:6 scale models) are designed and made considering the similarity, the manufacture scale accuracy, and the experimental practicability (see details in Figure 1 and Table 1).

Additionally, the details of the materials are as follows. The mixture ratio of concrete is such that cement: water: sand: 
TABLE 2: Mechanical property of reinforced steel.

\begin{tabular}{lcccc}
\hline Steel type & $\begin{array}{c}\text { Nominal diameter } \\
d(\mathrm{~mm})\end{array}$ & $\begin{array}{c}\text { Yield strength } \\
f_{\mathrm{y}}(\mathrm{MPa})\end{array}$ & $\begin{array}{c}\text { Strength } \\
f_{\mathrm{u}}(\mathrm{MPa})\end{array}$ & $\begin{array}{c}\text { Elastic modulus } \\
E_{\mathrm{s} \& \mathrm{p}}(\mathrm{GPa})\end{array}$ \\
\hline Q235 & 8 & 310.0 & 455.0 & 211.0 \\
HRB335 & 10 & 405.0 & 575.0 & 203.0 \\
Steel strand 1860 & 15.24 & 1795.0 & 1929.0 & 196.0 \\
\hline
\end{tabular}

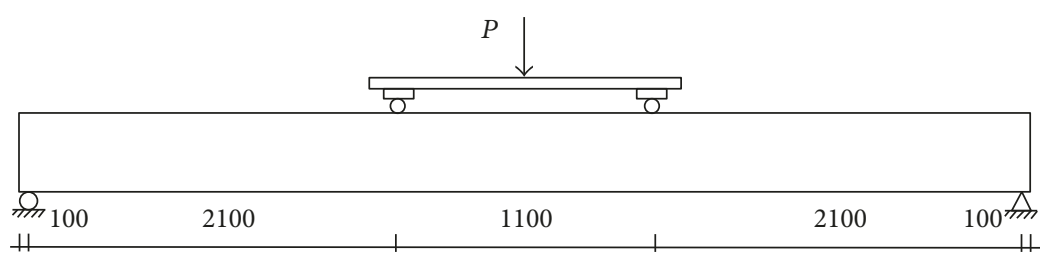

FIGURE 2: Experimental setup (unit: mm).

TABle 3: Details of specimens and loading conditions.

\begin{tabular}{|c|c|c|c|c|c|c|c|c|}
\hline \multirow{2}{*}{ Specimen } & \multicolumn{5}{|c|}{ Loading $(\mathrm{kN})$} & \multirow{2}{*}{ FRP-OFBG } & \multicolumn{2}{|c|}{ Fatigue life $\left(10^{6}\right)$} \\
\hline & $P_{\min }$ & $P_{\max }$ & $\Delta P$ & $P_{\mathrm{u}}$ & $L=P_{\max } / P_{\mathrm{u}}(-)$ & & $N_{\mathrm{f}}$ & $N_{0.2}$ \\
\hline Number 1 & - & - & - & 158.6 & - & Yes & - & - \\
\hline Number 2 & - & - & - & 180.0 & - & No & - & - \\
\hline Number 3 & 27.2 & 90.6 & 63.4 & - & 0.60 & Yes & 0.917 & 0.480 \\
\hline Number 4 & 27.2 & 82.7 & 55.5 & - & 0.55 & Yes & 1.405 & 0.951 \\
\hline Number 5 & 27.2 & 74.7 & 47.5 & - & 0.50 & Yes & 1.769 & 1.100 \\
\hline Number 6 & 27.2 & 66.8 & 39.6 & - & 0.45 & Yes & 2.162 & 1.252 \\
\hline Number 7 & 27.2 & 62.2 & 35.0 & - & 0.35 & Yes & 2.107 & 1.830 \\
\hline Number 8 & 27.2 & 85.4 & 58.2 & - & 0.50 & No & 2.690 & 2.077 \\
\hline Number 9 & 27.2 & 76.4 & 49.2 & - & 0.45 & No & 3.676 & 3.251 \\
\hline Number 10 & 27.2 & 62.2 & 35.0 & - & 0.35 & No & 4.646 & 3.256 \\
\hline Number 11 & 27.2 & 62.2 & 35.0 & - & 0.35 & No & 3.497 & 2.876 \\
\hline Number 12 & 27.2 & 62.2 & 35.0 & - & 0.35 & No & 2.954 & 2.751 \\
\hline
\end{tabular}

aggregate $:$ admixture $=380: 155: 720: 1084: 120\left(\right.$ unit $\left.: \mathrm{kg} / \mathrm{m}^{3}\right)$. The cement is Portland cement of P.II $42.5 \mathrm{R}$, the water is tap water, the aggregates are crushed limestone with diameters of approximately $5 \sim 20 \mathrm{~mm}$, the sands are middle grain sands, the mineral admixtures are mineral powder of S95 and fly ash, and the water-reducing agent is named as NoF-II with admixture quantity of $5.15 \mathrm{~kg} / \mathrm{m}^{3}$. The concrete strength is in the range of $44.0-66.0 \mathrm{MPa}$, and its mean value is 53.6 MPa. The mechanical property of the reinforced steel is tested following the Chinese standard [18] and listed in Table 2.

Furthermore, the prestressed steel strands are tensioned on both beam ends after a curing of 28 days, anchored at the ends, and sealed with the cement grouting. To reduce the influence of shrinkage and creep of concrete, all specimens have been stored in the laboratory for more than six months.

2.2. Experimental Setup. The four-point bending loading method is applied in the experiment (Figure 2), with the loading points calculated by the wheelbase of the train [1-3]. Two specimens are employed to test the static ultraload $P_{\mathrm{u}}$ and make sure the specimens are designed as the reinforced beams, and the other 10 specimens are used to be investigated on the fatigue performance deterioration (see Table 3).

The fatigue loads are calculated as follows. Initially, the minimum load $P_{\min }$ is estimated by the equivalent bending moment of the scale model compared with the standard beam under static load, considered an increasing $20 \%$ of the load due to the replacement of the former lighter sleepers by new heavier ones (Table 3). Furthermore, the maximum load $P_{\max }$ is estimated by the equivalent bending moment under both static and live loads, that is, the basic maximum load is $P_{\max }=62.2 \mathrm{kN}$ with the load level $L=P_{\max } / P_{\mathrm{u}}=0.35$ in Table 3. The other maximum loads are $P_{\max }=0.40 P_{\mathrm{u}}$, $0.45 P_{\mathrm{u}}, 0.50 P_{\mathrm{u}}, 0.55 P_{\mathrm{u}}$, and $0.60 P_{\mathrm{u}}$, with load levels $L=0.40$, $0.45,0.50,0.55$, and 0.60 in Table 3 , taking into account a higher quality of the specimens compared with the standard beams on site. 
2.3. Multisensor System. The multisensor system consisted of the strain sensors, the static and dynamic deflection/displacement sensors, and the corresponding data acquisition systems, in order to monitor the performance deterioration of the bridges under fatigue loading. The details of the system are as follows.

Initially, the strains of the concrete, rebar, and prestressed strand on the midspan were monitored by using the smart fiber-reinforced polymer (FRP) and electrical resistance strain gauges. The smart FRP is named as the FRP optical fiber Bragg grating (FRP-OFBG, Table 3) and it was used as a reinforcement and strain sensor with a resolution of $1 \mu \varepsilon$ in this work. In detail, it is one of the new smart opticalfiber-sensor-based structures combined with FRP (e.g., FRP-OFBG composite rebar, boards, tubes, and sheets), and it is developed by the research groups of fiber sensors for structural-health monitoring in Dalian University of Technology and Harbin Institute of Technology. The FRPOFBGs generally can act simultaneously as strain sensors and reinforcing components and can detect slips and cracks in RC structures. They are characterized by small dimensions, good resolution and accuracy, excellent durability, a wide range of operating temperature, and good signal transmission over long distances. For the purpose of strain monitoring, the force transferred from the host material to the grating region of the fiber core causes the length of the grating region to change and the refractive index of the core section to vary accordingly. When the light is illuminated from the broadband source via the coupler, part of this light is reflected back to the coupler and the reflected wavelength is detected by the optical spectrum analyzer. The strain variation in the grating region is then simply determined by measuring the change in the reflected wavelength from the FRP-OFBG sensor. These sensors have been shown to possess a linear relationship between the strain and the reflected wavelength shift, provided that the elastic deformation limit of the fiber is not exceeded.

Additionally, the linear variable displacement transducer (LVDT) and the accelerometer of type 891-II were used to monitor the static and dynamic deflections, respectively, on the midspan, the points on 1/4 span from the supports, and two supports. The resolution of the accelerometer is $1 \times 10^{-7} \mathrm{~mm}$, the measurement range is $0-70 \mathrm{~mm}$, and the effective frequency range is $1-100 \mathrm{~Hz}$.

Therefore, the multisensor system used in the test is characterized by good resolution and accuracy and excellent durability for monitoring the performance deterioration of heavy-haul railway bridges under fatigue loading. By using this system, it is able to monitor the performance deterioration in the aspect of both structural response and material degradation and further to better understand the mechanism of the deterioration.

\section{Experimental Results}

3.1. Static Experimental Results. The static experiments were conducted after the standard for test method of concrete structures (GB50152-92) [19]. The experimental results verified that the designed beams were reinforced beams with a

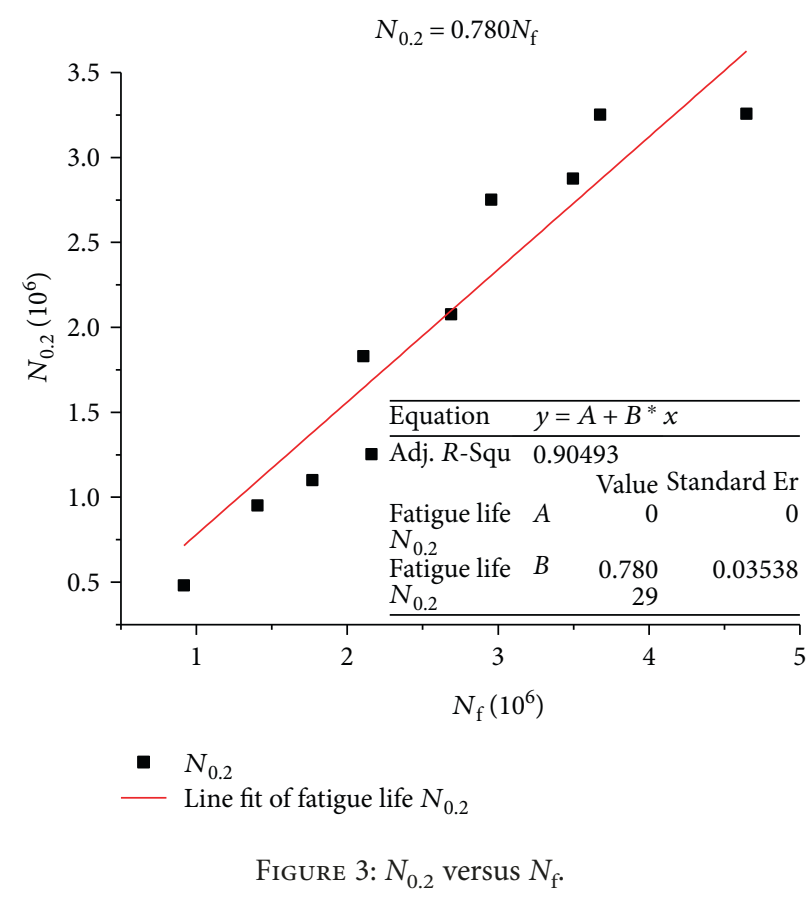

typical bending failure mode. Additionally, the static ultraload $P_{\mathrm{u}}$ of the specimen numbers 1 and 2 is listed in Table 3. Since the FRP-OFBG in specimen number 1 has a lower mechanical property than that of the steel strands in specimen number 2 , the specimen number 1 obtains a lower scalar of $P_{\mathrm{u}}$. Therefore, the load level of the specimens in the fatigue experiments is calculated by the static ultraloads with/without FRP-OFBG (Table 3).

\subsection{Fatigue Experimental Results}

3.2.1. Failure Mode. All specimens under fatigue loading obtained the same failure mode such that the failure of the rebars at the bottom started the specimen failure. Furthermore, the dominant cracks are located at two positions approximately the midspan and the loading point for specimen numbers $3,4,6,9$, and other specimens.

3.2.2. Fatigue Life. Since the bridge is estimated to be under serviceability limit state when there is a crack with a width of $0.2 \mathrm{~mm}$, after the code TB10002.3-2005 [20], the allowable fatigue life $\left(N_{0.2}\right)$ is defined as the cycle number when the width of a crack reaches $0.2 \mathrm{~mm}$ of the specimen. Furthermore, the fatigue life $\left(N_{\mathrm{f}}\right)$ is defined as the cycle number relating to the first failure of the rebar.

Therefore, $N_{0.2}$ and $N_{\mathrm{f}}$ are listed in Table 3. And the linear relationship between $N_{0.2}$ and $N_{\mathrm{f}}$ is proposed such that (Figure 3)

$$
N_{0.2}=0.780 N_{\mathrm{f}} .
$$

3.2.3. Midspan Deflection. The variation of midspan deflection depending on the cycle number is obtained and the typical results are plotted in Figures 4(a) and 4(b). It is found that the response of load-midspan deflection is almost linear and the slope of the response varies depending on the cycle 


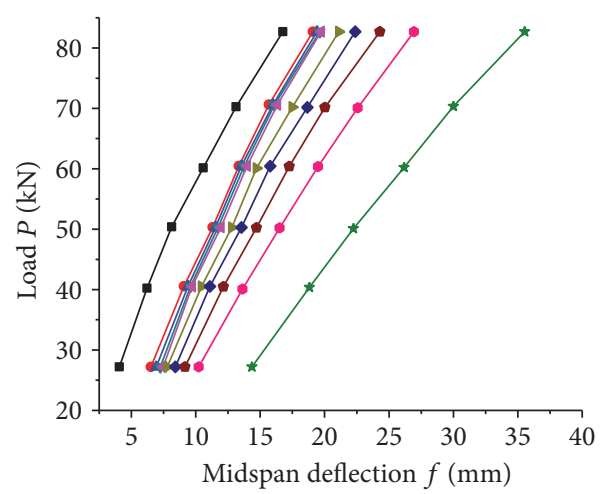

$\rightarrow 0.00$ million cycles $\rightarrow-0.50$ million cycles

$\rightarrow 0.01$ million cycles $\rightarrow 0.75$ million cycles

$\neg 0.05$ million cycles $\rightarrow-1.00$ million cycles

$\rightarrow 0.10$ million cycles $\rightarrow-1.25$ million cycles

$\leftarrow 0.25$ million cycles $\nleftarrow-1.40$ million cycles

(a) $P-f$ (specimen number 4$)$

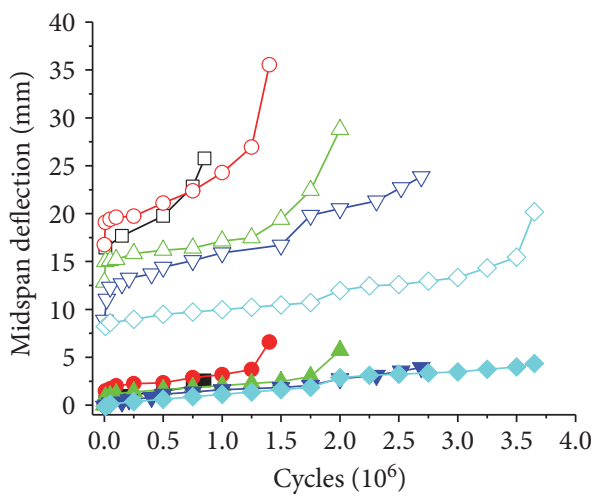

- $f$ min-0.60-No. $3 \triangle f$ max-0.50-No. 5

$\neg f$ max-0.60-No. $3 \rightarrow f$ min-0.45-No. 6

$\rightarrow f$ min-0.55-No. $4 \quad \rightarrow-f$ max-0.45-No. 6

$-\circ f$ max-0.55-No. $4 \multimap f$ min-0.40-No. 7

$\neg f$ min-0.50-No. $5 \leadsto f$ max-0.40-No. 7

(c) $f-N$ (specimen number 3-number 7)

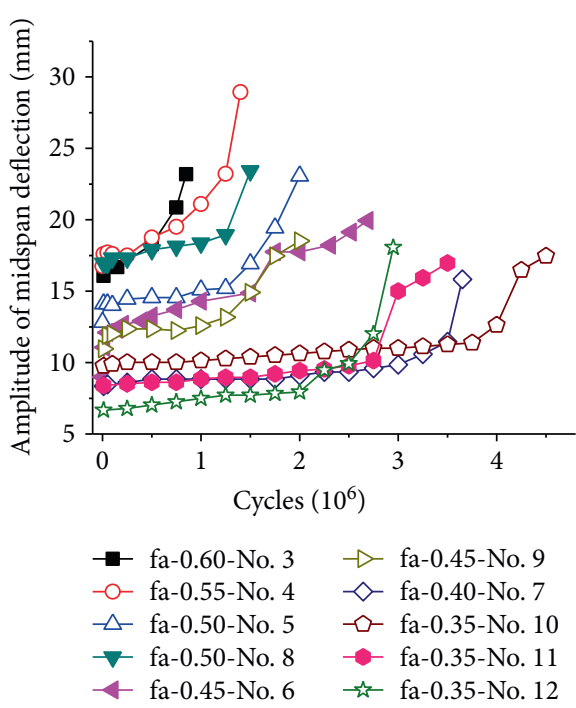

(e) $\Delta f-N$

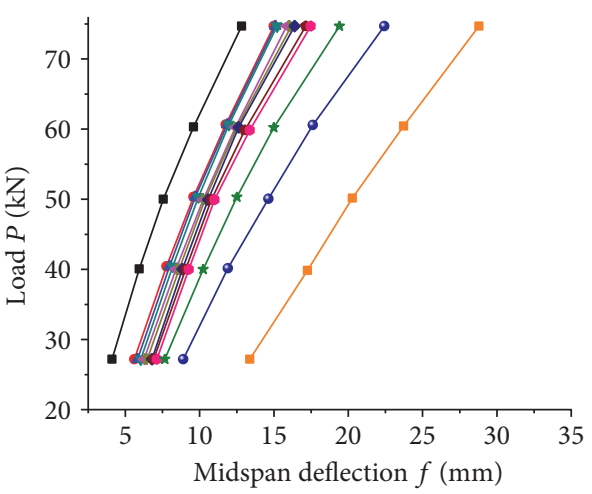

$\rightarrow 0.00$ million cycles $\rightarrow-0.75$ million cycles

$\rightarrow 0.01$ million cycles $\bullet-1.00$ million cycles

$\triangle 0.05$ million cycles $\rightarrow 1.25$ million cycles

$\rightarrow 0.10$ million cycles $\rightarrow 1.50$ million cycles

$\leftarrow 0.25$ million cycles $\rightarrow-1.75$ million cycles

$\rightarrow 0.50$ million cycles $\rightarrow-2.00$ million cycles

(b) $P$ - $f$ (specimen number 5)

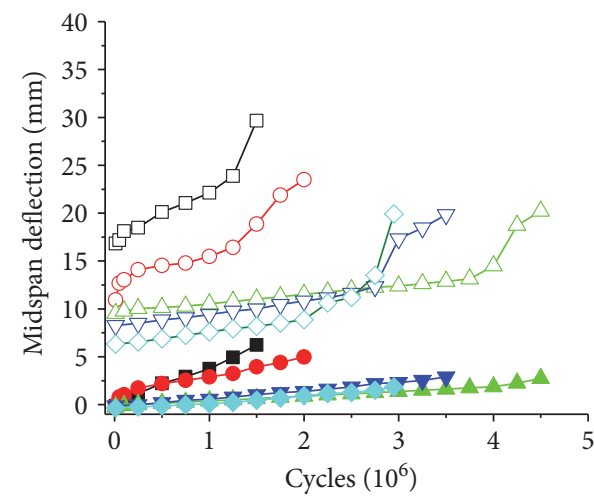

$\rightarrow f$ min-0.50-No. $8 \triangle-f$ max-0.35-No. 10

$\neg-f$ max-0.50-No. $8 \rightarrow f$ min-0.35-No. 11

$\rightarrow f$ min-0.45-No. $9 \rightarrow-f$ max-0.35-No. 11

$-\circ f \max -0.45$-No. $9 \multimap f$ min-0.35-No. 12

- $f$ min-0.35-No. $10 \curvearrowright f$ max-0.35-No. 12

(d) $f-N$ (specimen number 8-number 12) 


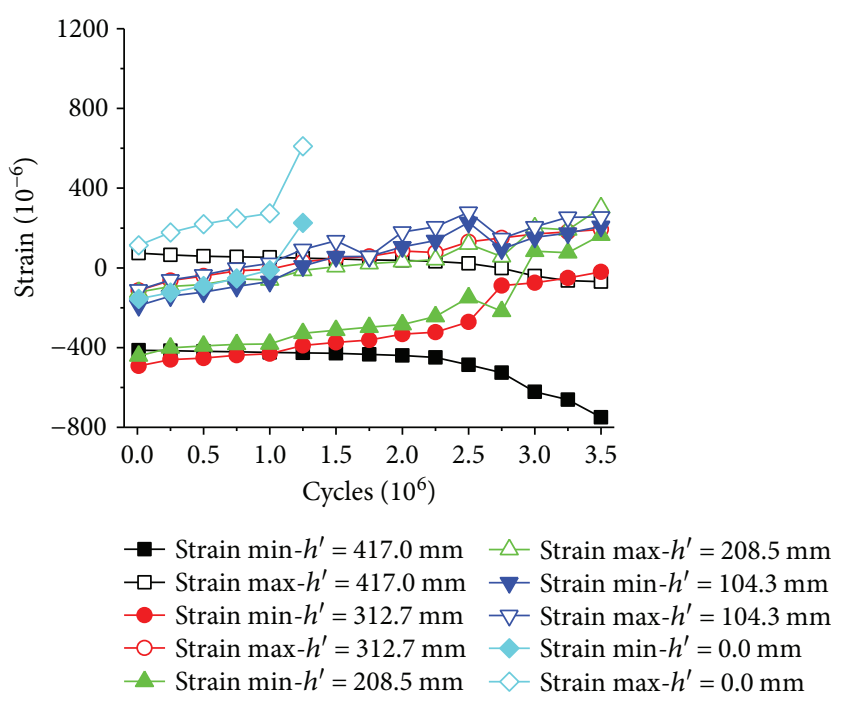

(a) $\varepsilon_{\mathrm{c}}-N$ (concrete strain for specimen number 11)

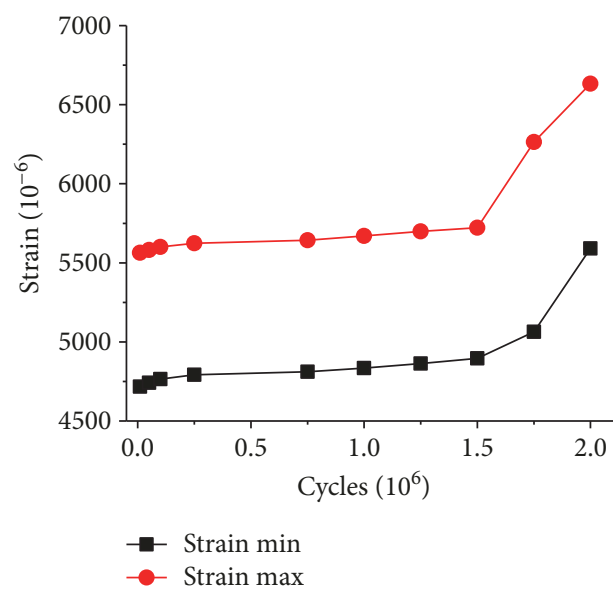

(c) $\varepsilon_{\mathrm{p}}-N$ (prestressed strand strain for specimen number 11)

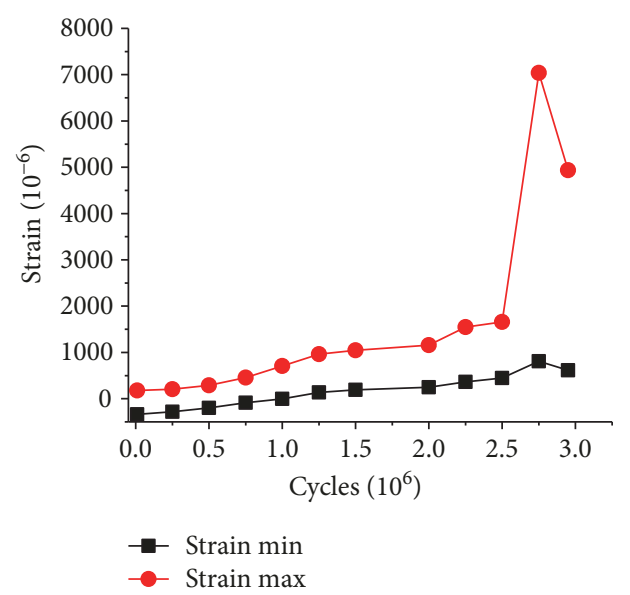

(e) $\varepsilon_{\mathrm{s}}-N$ (steel rebar strain for specimen number 11)

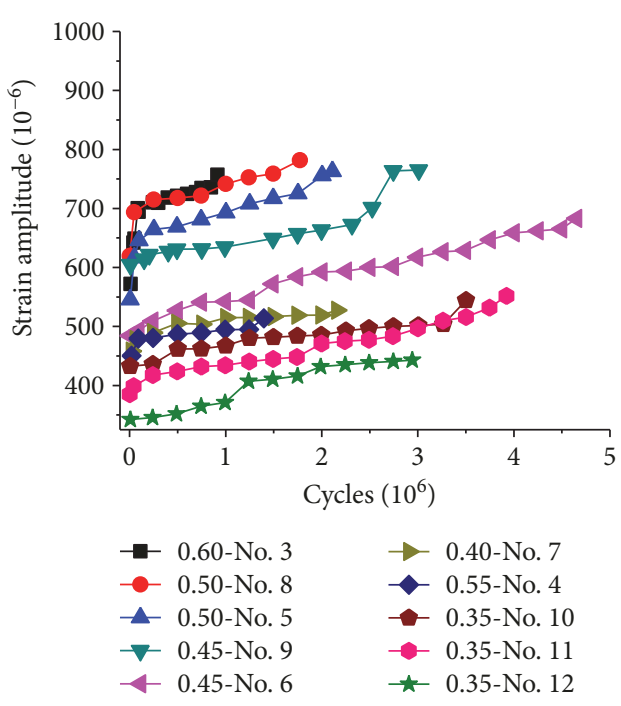

(b) $\Delta \varepsilon_{\mathrm{c}}-N\left(h^{\prime}=417.0 \mathrm{~mm}\right)$

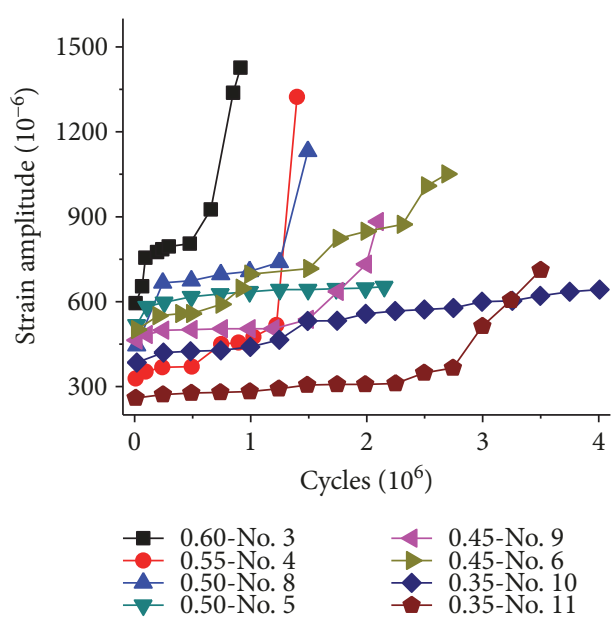

(d) $\Delta \varepsilon_{\mathrm{p}}-N$

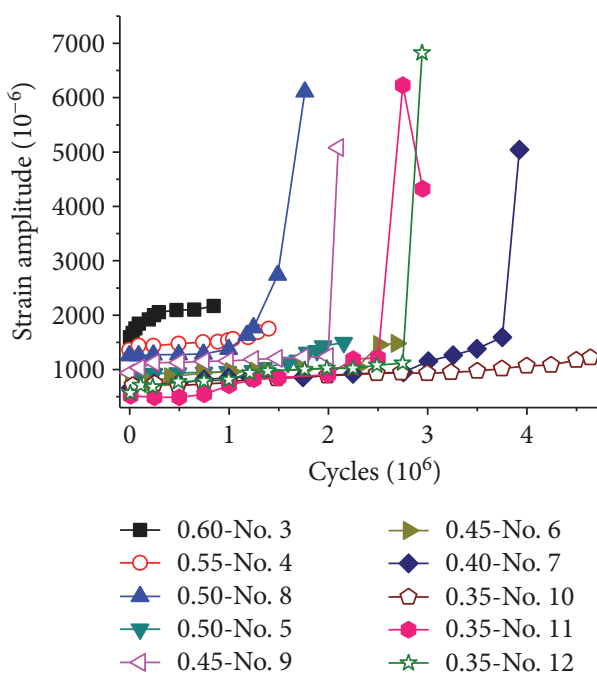

(f) $\Delta \varepsilon_{\mathrm{s}}-N$

FIGURE 5: Variation of material strain and its amplitude on the midspan during fatigue life $\left(h^{\prime}\right.$ denotes the depth of the sensor on the midspan section). 


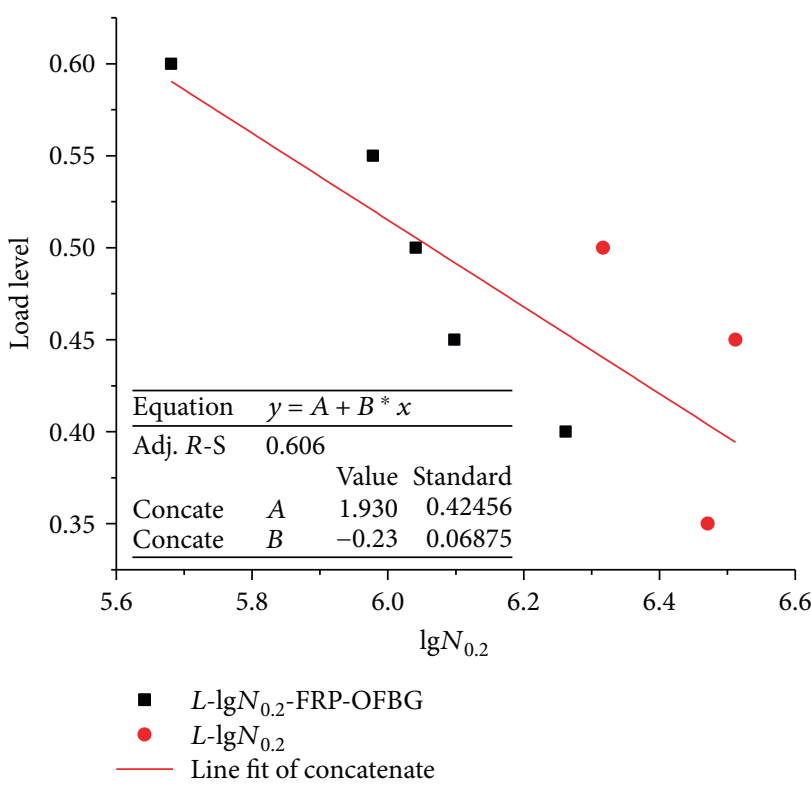

(a) $L-\lg N_{0.2}$

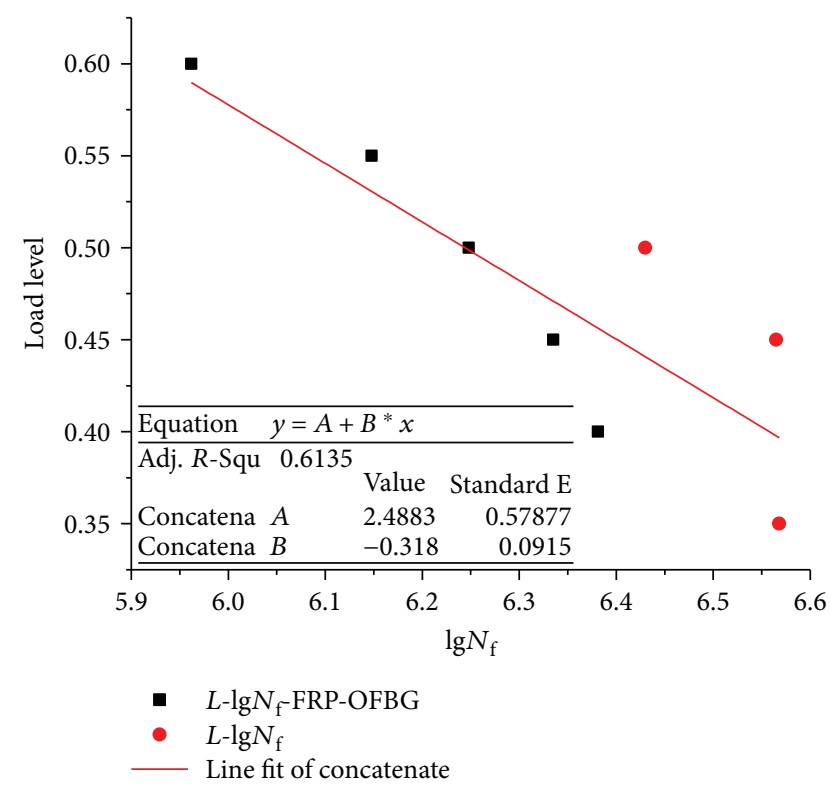

(b) $L-\lg N_{\mathrm{f}}$

FIgURE 6: Relationships of $L-\lg N_{0.2}$ and $L-\lg N_{\mathrm{f}}$.

number in three stages: quickly reducing, slowly reducing, and quickly reducing again.

Furthermore, the variation of the maximum, minimum, and amplitude of the midspan deflection depending on the cycle number also experiences a three-stage process (Figures 4(c)-4(e)).

3.2.4. Material Strain Development. Observing on the variation of material strain development and its amplitude depending on the cycle number in Figure 5, it is found that they experience the three-stage process. Specifically, the material strain development and its amplitude on the midspan develop in a three-stage process of the increasing rate: quickly increasing, slowly increasing, and quickly increasing again.

\section{Discussion}

4.1. S-N Model. The relationship between load level and fatigue life $(L-N)$ and the relationship between load range and fatigue life $(\Delta P-N)$ are plotted in Figures 6 and 7, respectively, based on the results listed in Table 3 . And the results of $\triangle P$ obtain a better linear dependence on $N$ in Figure 7 than that on $L$ in Figure 6, which may be due to the initial elastic response of the rebar at the bottom $\Delta \sigma$ caused by the load range $\Delta P$ (see the linear relationship of $\Delta \sigma-\Delta P$ in Figure $7(\mathrm{c}))$.

Additionally, observing on the typical $S-N$ relationship, that is, the relationship between the stress range (or its denary logarithm) of the rebar at the bottom and the cycle number in Figures $8(\mathrm{a})$ and $8(\mathrm{~b})$, the $S-N$ model by fitting the experimental results is obtained such that

$$
\begin{aligned}
\Delta \sigma_{\mathrm{r}} & =2149.32-308.69 \lg N_{\mathrm{f}}, \\
\lg \left(\Delta \sigma_{\mathrm{r}}\right) & =6.446-0.661 \lg N_{\mathrm{f}} .
\end{aligned}
$$

Equations (2) and (3) show that the fatigue life of specimens is determined by the fatigue life of the rebar at the bottom, which agrees with the experimental results in literature [8-15]. The fatigue life of specimens decreases when the stress range (or its denary logarithm) of the rebar increases.

Furthermore, the $S-N$ model in (2) or (3) is able to be used to predict the specimen fatigue life considering the stress range of the rebar. The predictions are plotted in Figure $8(\mathrm{c})$, comparing with the predictions of other $S-N$ models [10, 21, 22].

Figure 8 (c) illustrates that, firstly, the predictions of the model in this work are more agreeable with the experimental results than those of other models [10, 21, 22]. Secondly, though the models $[10,22]$ predict a close fatigue life $\left(N_{\mathrm{f}} \approx 200 \times 10^{6}\right)$ when the stress range of the rebar $\sigma_{\mathrm{r}} \approx 200 \mathrm{MPa}$, the model proposed in this work predicts a lower fatigue life when $\Delta \sigma_{\mathrm{r}}<200 \mathrm{MPa}$, and a higher fatigue life when $\Delta \sigma_{\mathrm{r}}>200 \mathrm{MPa}$, compared with that of the other models $[10,22]$. The reason can be concluded that the performance deterioration of the specimens supplies a specific stress state variation for the rebar at the bottom in this work which is different from that in literature $[10,22]$, due to the different processes of material degradation (e.g., the concrete degradation caused by fatigue cracks [10, 23-26], the prestressed strand degradation resulted from fatigue plasticity [27]), specimen stiffness degradation and curvature variation [8-14], and so forth. Thirdly, the corrosion of the rebar generally results in an obvious reduction of specimen fatigue life $[4,6,8,21]$. It causes an obviously lower fatigue life predicted by the model [21] compared with that by the other models (Figure $8(\mathrm{c})$ ); therefore, the corrosion of rebar influences the fatigue life of the bridge.

4.2. Damage Evolution Model. It is found that the slope of the $P-f$ response (i.e., the specimen stiffness) decreases and the 


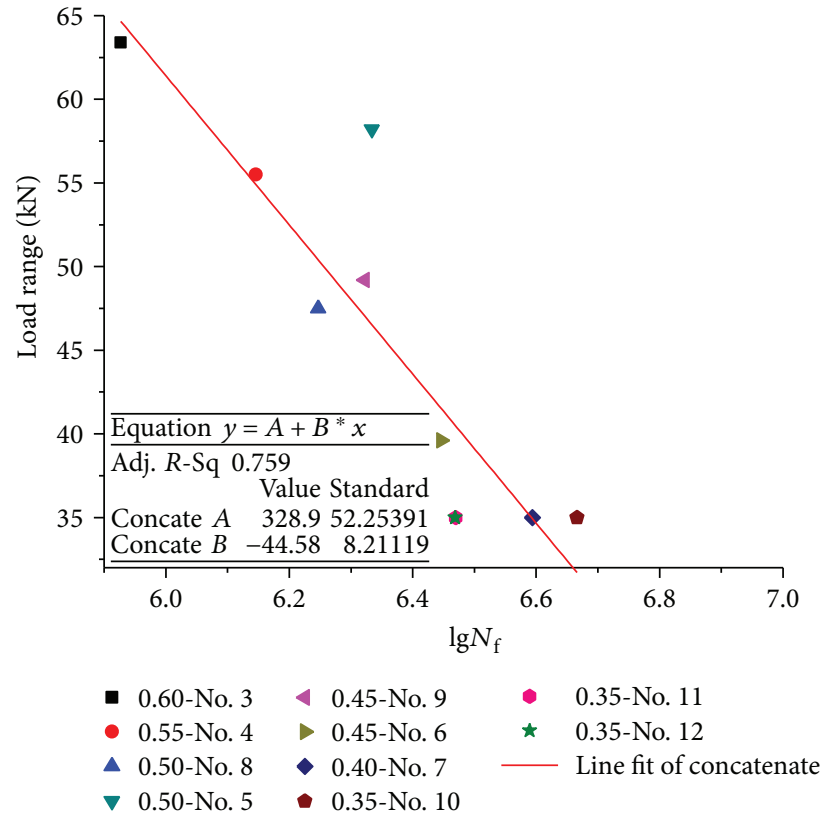

(a) $\Delta P-\lg N_{f}$

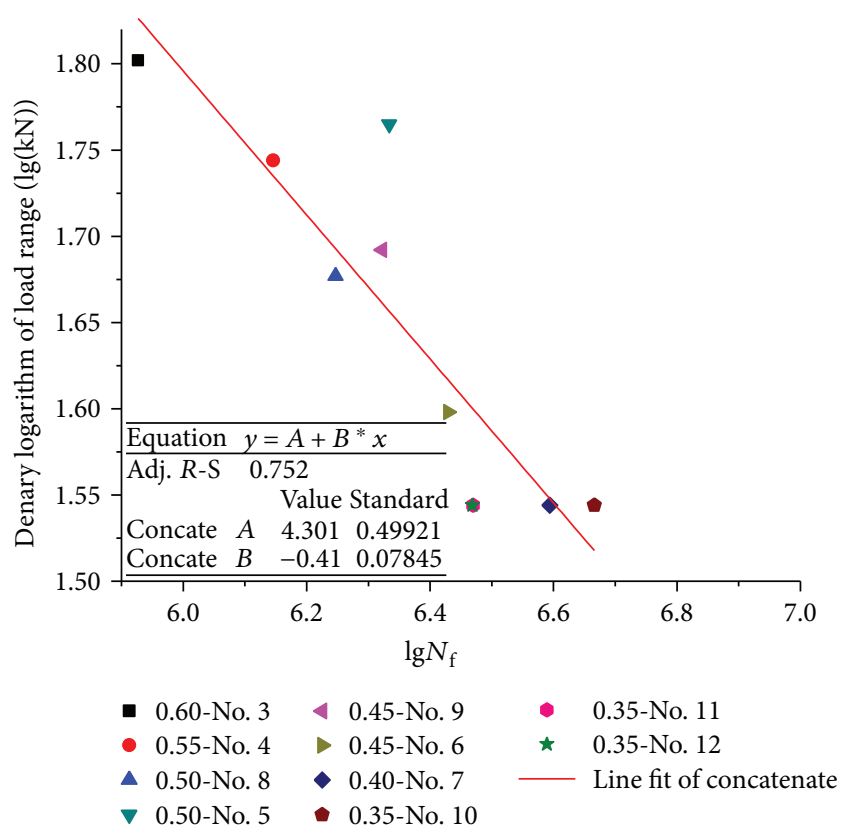

(b) $\lg (\Delta P)-\lg N_{\mathrm{f}}$

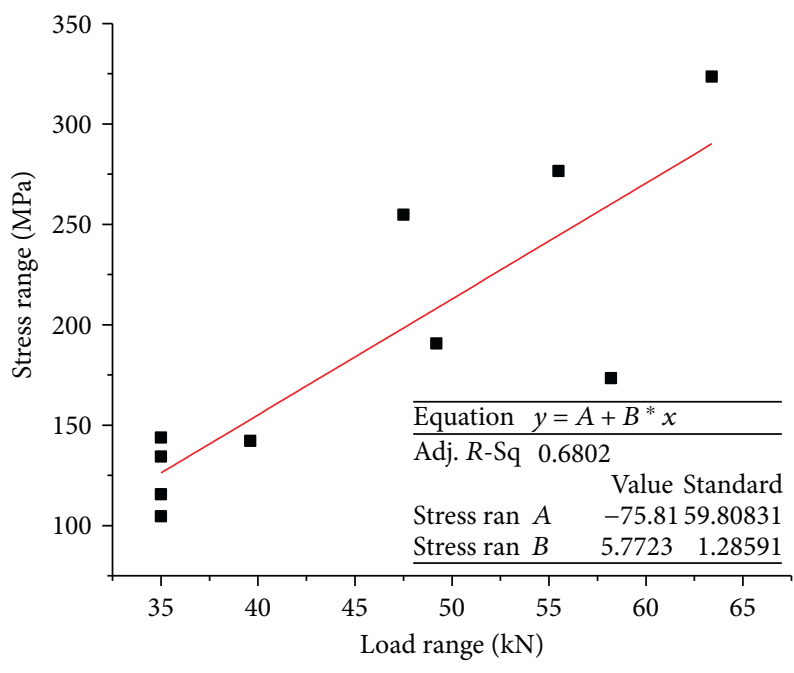

- Stress range Line fit of stress range

(c) $\Delta \sigma-\Delta P$

Figure 7: Relationships of $\Delta P-\lg N_{\mathrm{f}}, \lg (\Delta P)-\lg N_{\mathrm{f}}$, and $\Delta \sigma-\Delta P$.

residual midspan deflection (i.e., the specimen residual/ inelastic deformation) develops with the increasing of the cycle number, by observing on the $P-f$ response in Figures 4(a) and 4(b). Therefore, an elastic damage variable $D_{\mathrm{e}}$ according to specimen stiffness degradation and an inelastic damage variable $D_{\mathrm{i}}$ responding to specimen inelastic deformation are defined, respectively, in this work, such that

$$
\begin{aligned}
& D_{\mathrm{e}}=\frac{P_{\mathrm{de}}}{P_{0}}=\frac{f_{\mathrm{de}},}{f}, \\
& D_{\mathrm{i}}=\frac{P_{\mathrm{di}}}{P_{0}}=\frac{f_{\mathrm{di}}}{f},
\end{aligned}
$$

where $P_{\mathrm{de}}$ and $P_{\mathrm{di}}$ denote the elastic and inelastic damagecaused load reductions, respectively (similar to the elastic and inelastic damage-caused stress reduction, respectively in literature $[24,25]) ; f_{\mathrm{de}}$ and $f_{\mathrm{di}}$ denote the elastic and inelastic damage-caused midspan deflections, respectively; $P_{0}$ denotes the idealized load without damage in the specimen (similar to the effective stress $[24,25]) ; f$ denotes the total midspan deflection.

Further, a (total) damage variable $D$ is defined as follows:

$$
D=D_{\mathrm{e}}+D_{\mathrm{i}}=\frac{\left(P_{\mathrm{de}}+P_{\mathrm{di}}\right)}{P_{0}}=\frac{\left(f_{\mathrm{de}}+f_{\mathrm{di}}\right)}{f},
$$




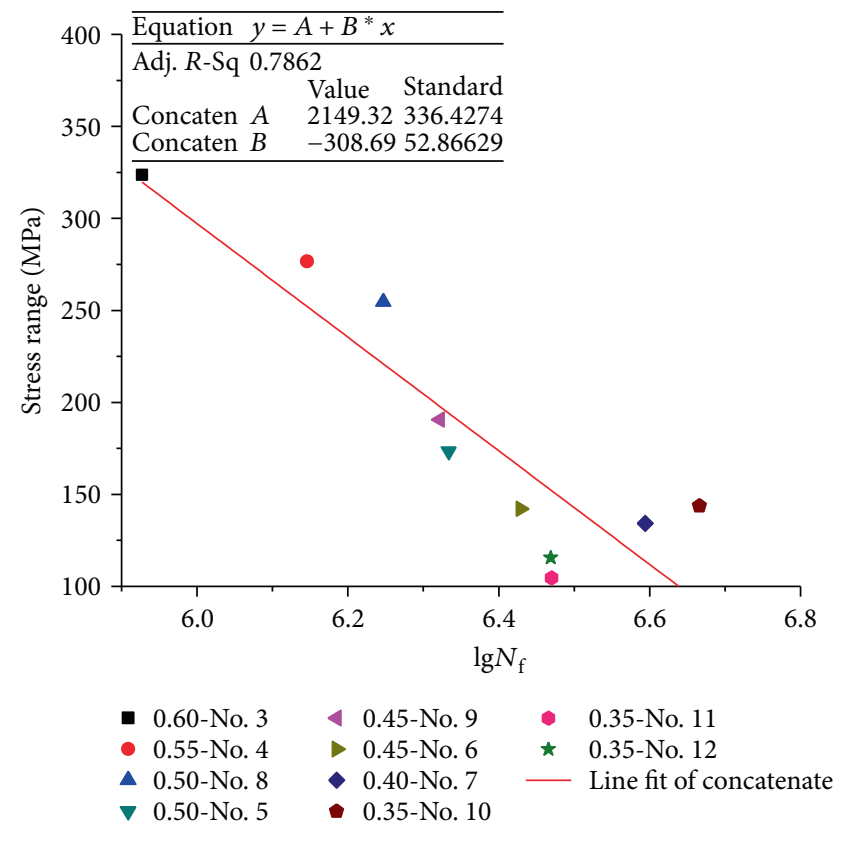

(a) $\Delta \sigma_{\mathrm{r}}-\lg N_{\mathrm{f}}$

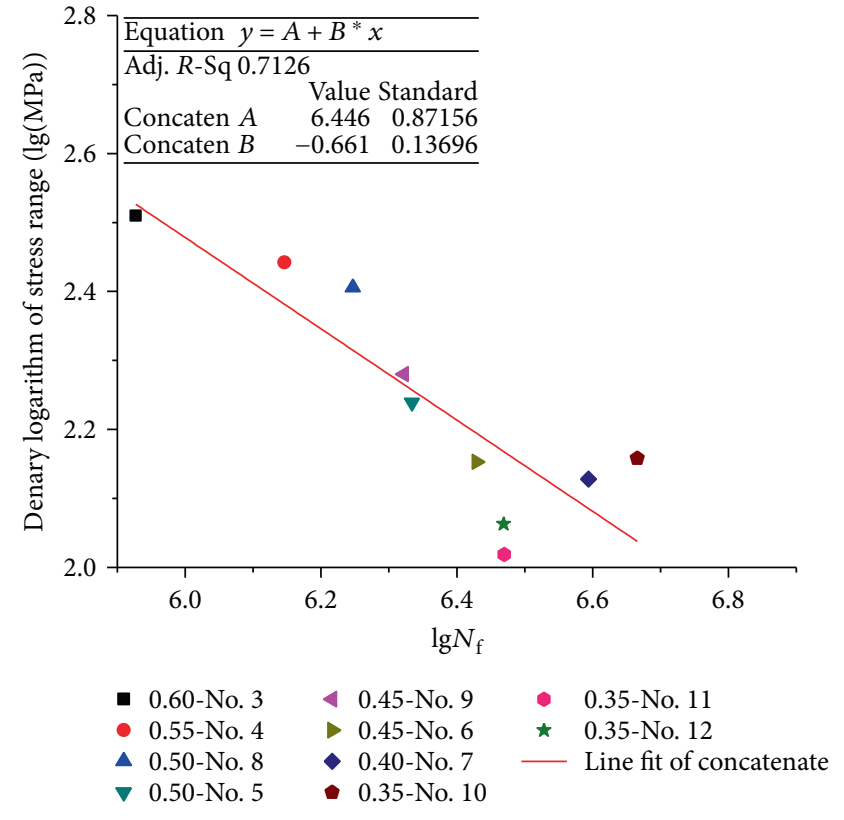

(b) $\lg \left(\Delta \sigma_{\mathrm{r}}\right)-\lg N_{\mathrm{f}}$

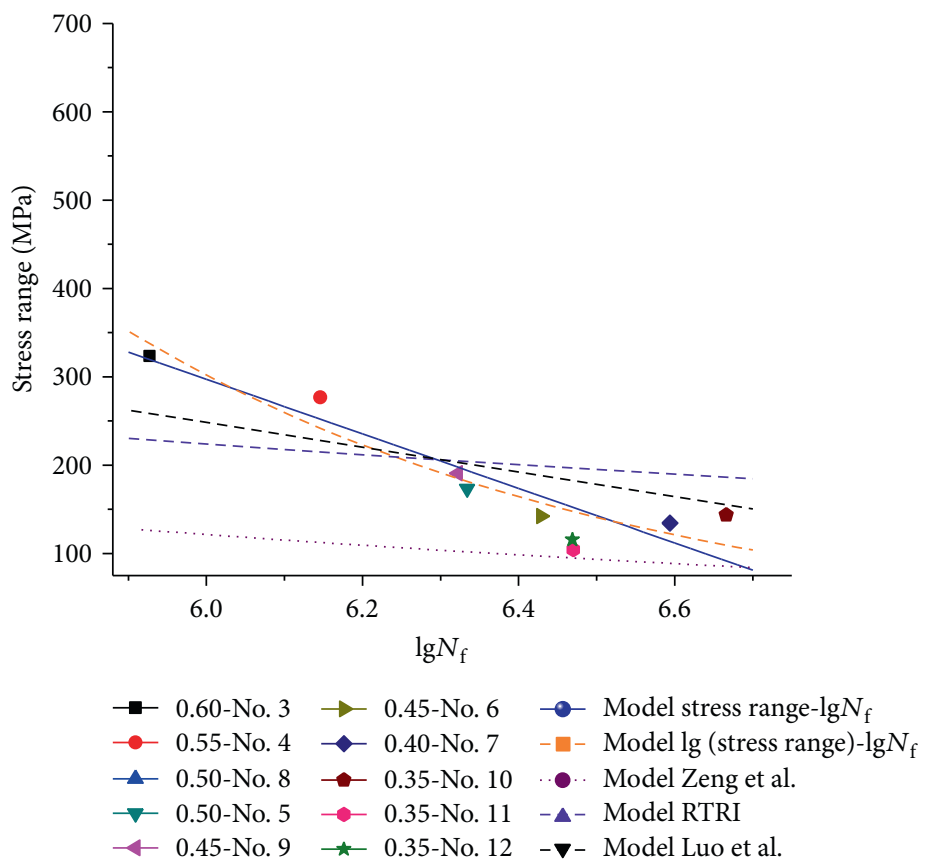

(c) Comparison of relationship of $\Delta \sigma_{\mathrm{r}}-\lg N_{\mathrm{f}}$ by the proposed and other models

$[10,21,22]$

Figure 8: $S-N$ model.

where the relationship between $D_{\mathrm{e}}$ and the current specimen stiffness $E$ is expressed such that

$$
E=D_{\mathrm{e}}\left(1-D_{\mathrm{i}}\right) E_{0}=D_{\mathrm{E}} E_{0},
$$

where $D_{\mathrm{e}}$ denotes the elastic damage variable in the total midspan deflection space, $D_{\mathrm{E}}$ denotes the elastic damage variable in the elastic midspan deflection space $f_{\mathrm{E}}\left(f_{\mathrm{E}}=f-f_{\mathrm{di}}\right)$. Comparing with the damage variable $D_{\mathrm{E}}$ based on the specimen stiffness degradation in literature $[9,15]$, the damage variable $D$ in this work is more considerable for its characterization of the coupling of stiffness degradation and inelastic deformation.

Thus, the damage evolution is obtained in Figures 9(a)9(c). Figures 9(a)-9(c) illustrate that the damage evolution and elastic damage evolution (i.e., $D-N$ and $D_{\mathrm{e}}-N$ ) experience a three-stage process; however, the inelastic damage evolution $D_{\mathrm{i}}-N$ experiences only a two-stage process: the initial 

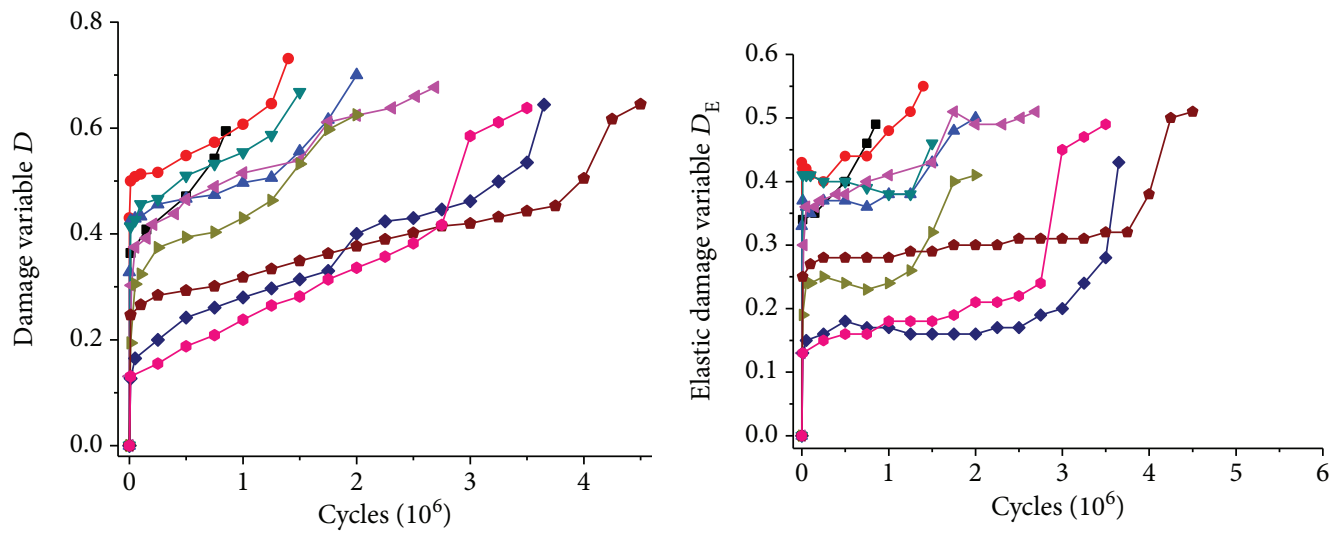

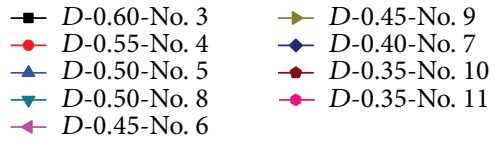

(a) $D-N$ (specimen numbers 3-11)

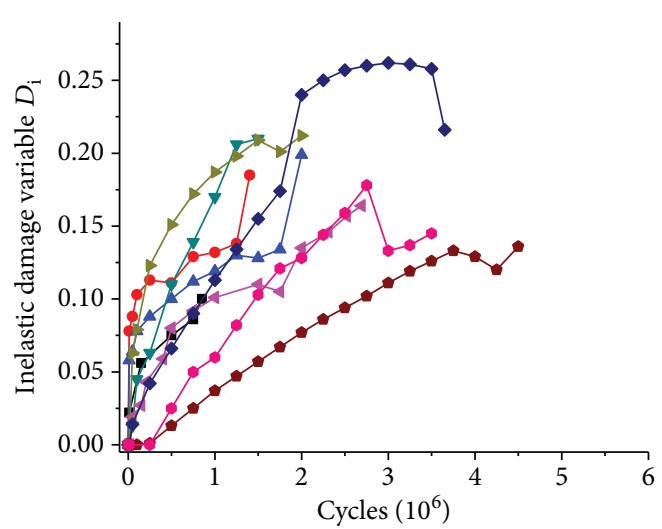

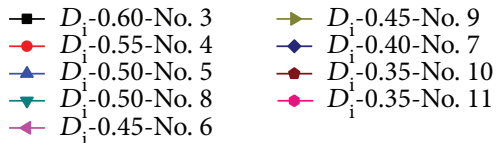

(c) $D_{\mathrm{i}}-N$ (specimen numbers 3-11)

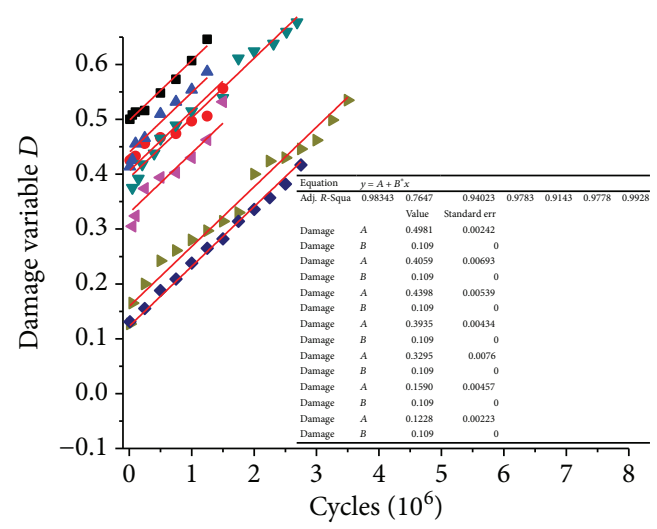

- $D-0.55-$ No. 4

- $D-0.50-$ No. 5

- $D$-0.50-No. 8

4 D-0.45-No. 9

D-0.40-No. 7

- D-0.35-No. 11

— Line fit of damage

(e) $D-N$ during the second stage

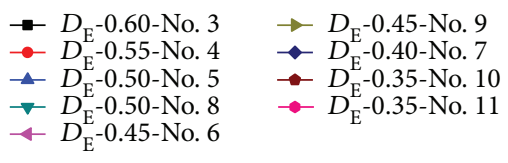

(b) $D_{\mathrm{E}}-N$ (specimen numbers 3-11)
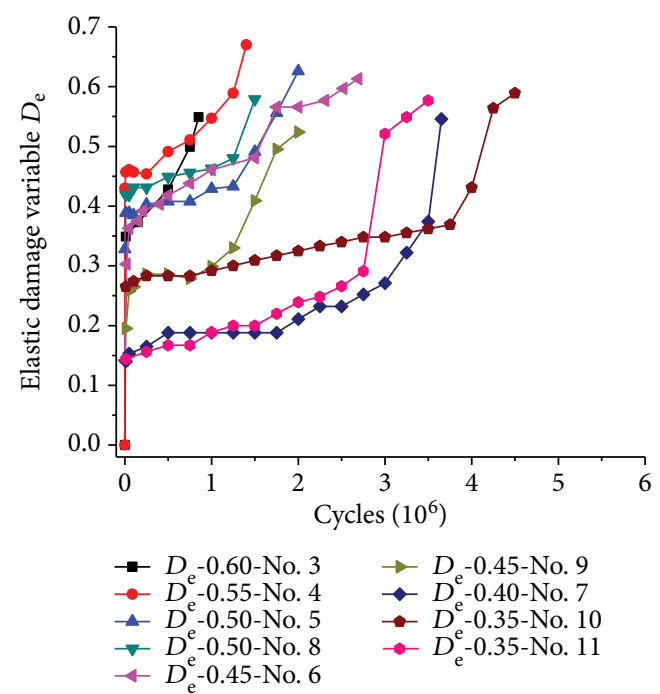

(d) $D_{\mathrm{e}}-\mathrm{N}$ (specimen numbers 3-11)

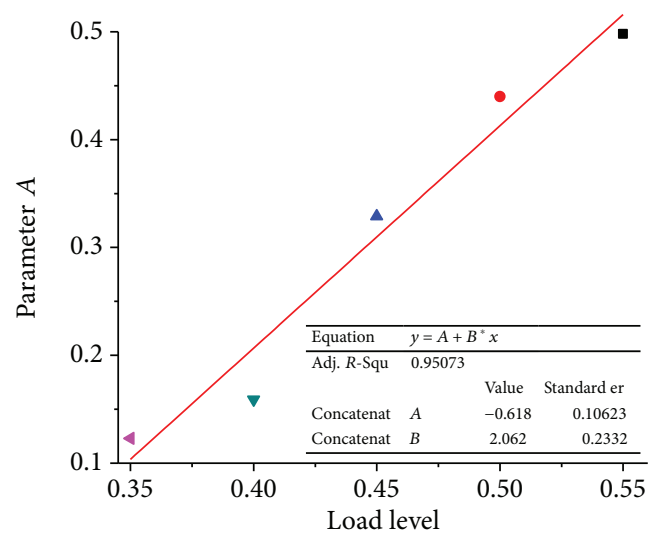

- $A$-0.55-No. $4 \quad \nabla A-0.40$-No. 7

- A-0.50-No. 8 A-0.35-No. 11

$\Delta$ A-0.45-No. 9 - Line fit of concatenate 


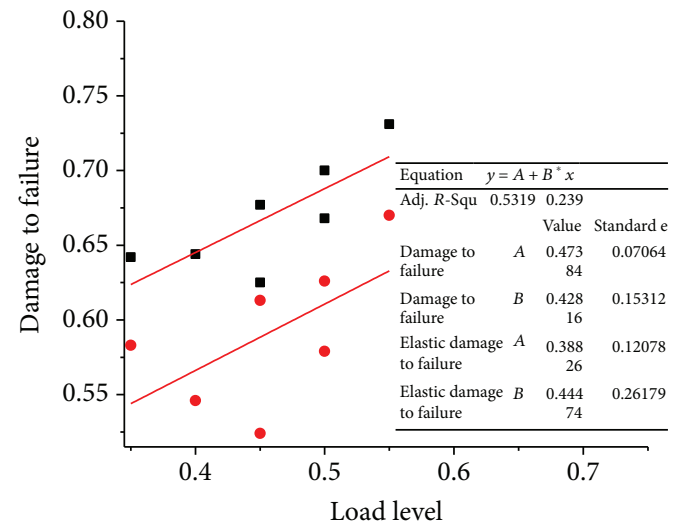

- $D_{\mathrm{f}} \quad$ - Line fit of damage to failure

- $D_{\mathrm{e}, \mathrm{f}} \quad$ - Line fit of elastic damage to failure

(g) $D_{\mathrm{f}}$ and $D_{\mathrm{e}, \mathrm{f}} L$ (specimen numbers 4-11)

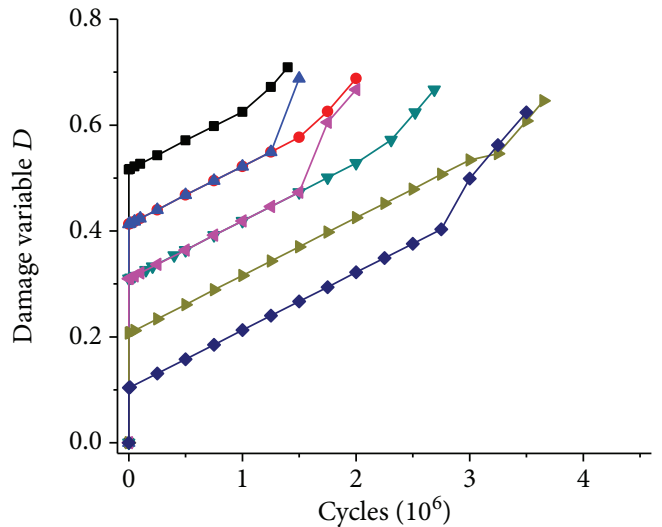

- D-0.55-No. 4 predicted $4 D-0.45$-No. 9 predicted $\rightarrow D-0.50$-No. 5 predicted $\rightarrow D-0.40-$ No. 7 predicted $\rightarrow D-0.50-$ No. 8 predicted $\rightarrow D-0.35-$ No. 11 predicted $\rightarrow D-0.45$-No. 6 predicted

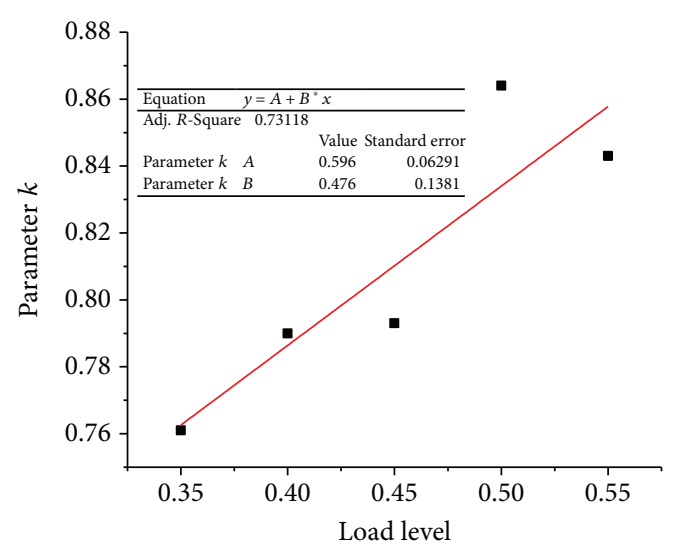

- $k$

- Line fit of parameter $k$

(h) $k$ - $L$ (specimen numbers $4,5,8,9$, and 11)

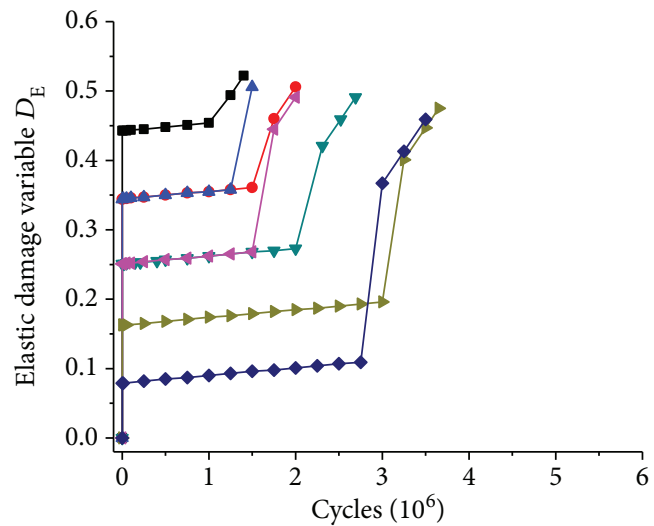

$\rightarrow D_{-}-0.55$-No. 4 predicted $4-D_{-}-0.45-$ No. 9 predicted $\rightarrow D_{\mathrm{E}}^{\mathrm{E}}-0.50$-No. 5 predicted $\rightarrow D_{\mathrm{E}}^{\mathrm{E}}-0.40$-No. 7 predicted $\neg D_{\mathrm{E}}-0.50$-No. 8 predicted $\multimap D_{\mathrm{E}}-0.35$-No. 11 predicted $\rightarrow D_{\mathrm{E}}-0.45-$ No. 6 predicted

(i) $\mathrm{D}-\mathrm{N}$ predicted

(j) $D_{\mathrm{E}}-N$ predicted

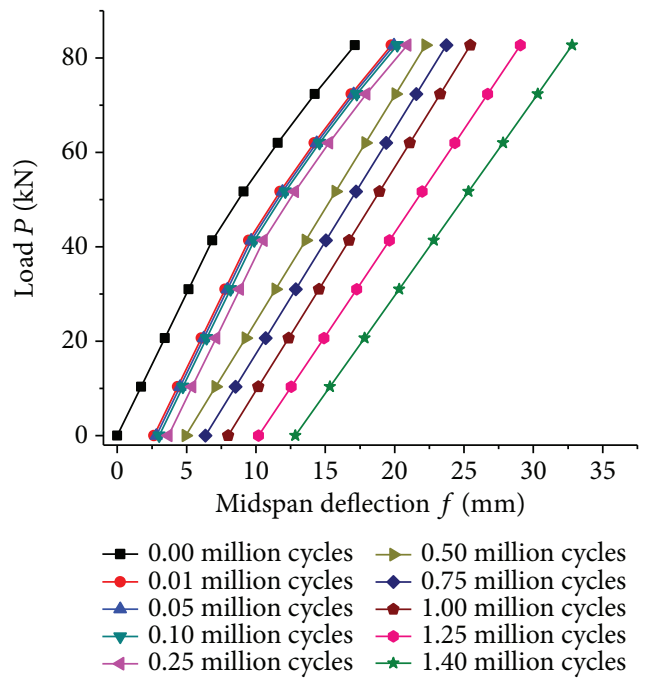

(k) $P$ - $f($ load level $L=0.50)$ predicted

Figure 9: Damage evolution, its related parameters (e.g., $D_{\mathrm{f}}, D_{\mathrm{e}, \mathrm{f}}, A$, and $k$ ), and predictions. 
linearly increasing and the subsequent increasing with a reduced rate.

The damage variable and the elastic damage variable to the fatigue failure are defined as $D_{\mathrm{f}}$ and $D_{\mathrm{e}, \mathrm{f}}$, respectively. The stochastic damage evolution of materials [21,24] generally caused the existence of the stochastic damage evolution of the bridges; hence, considering the shortage of statistical experimental results and the unavailability of stochastic analysis methods of the bridges, for simplicity, the variables $\left(D_{\mathrm{f}}\right.$ and $D_{\mathrm{e}, \mathrm{f}}$ ) are assumed to be linearly dependent on the load level $L$ (Figure $9(\mathrm{~g})$ ), as follows:

$$
\begin{gathered}
D_{\mathrm{f}}=0.474+0.428 L, \\
D_{\mathrm{e}, \mathrm{f}}=0.388+0.445 L .
\end{gathered}
$$

This assumed that the linear relationship will be verified or improved in the future with the help of further experimental results and stochastic analysis methods.

Additionally, by investigating on the damage evolution in Figure 9(a), it is concluded that the relationship of $D-N$ during the second stage is linear with an equal slope (Figure 9(e)), such that

$$
D=A+B \cdot N
$$

where $A$ denotes the damage variable $D_{1}$ after the first cycle, that is, $D_{1}=A$ (see Figures 9(a), 9(e), and 9(f)), and $B$ denotes the slope of the $D-N$ relationship. In this work, $A$ is proposed to follow the equation such that

$$
A=-0.618+2.062 L \text {. }
$$

And it is assumed that $B=0.109$ (Figure 9(e)).

Furthermore, since it is found that the elastic damage variable $D_{\mathrm{E}, 1}$ after the first cycle is approximately proportional to the damage variable $D_{1}$ (see Figures 9(a) and 9(b)); it is proposed that $D_{\mathrm{E}, 1}$ follows the equation such that

$$
D_{\mathrm{E}, 1}=k D_{1}=k A \text {. }
$$

And the slope of $D_{\mathrm{E}}-N$ relationship during the second stage is assumed to be $B_{\mathrm{E}}=0.1 * B=0.0109 \approx 0.011$ (Figure $9(\mathrm{j})$ ), by investigating on the elastic damage evolution in Figure 9(b).

Therefore, the damage evolution (i.e., $D-N, D_{\mathrm{E} \& \mathrm{e}}-N$, and $\left.D_{\mathrm{i}}-N\right)$ is able to be predicted by the proposed models in (8), (9), (10), (11), and (12) in Figures 9(i), 9(g), and 9(j); further, the $P-f$ response of the specimen is also able to be predicted in Figure 9(k). Figures 9(i), 9(g), 9(j), and 9(k) illustrate that the proposed damage evolution model is verified to be effective to characterize the damage evolution and mechanical response of the specimen, by comparing the predictions with the experimental results.

\subsection{Performance Deterioration of Heavy-Haul Railway} Bridges under Fatigue Loading. Based on the above investigation and analysis, it is concluded as follows.

Initially, according to the fatigue life, it is necessary to strengthen the heavy-haul railway bridge with a consideration of the environmental effects. In detail, Figure 8 and (2) show that the bridge subjected to the train loading with a 30-ton axle weight (i.e., $\Delta \sigma_{\mathrm{r}} \approx 120 \mathrm{MPa}$ ) satisfies the fatigue life requirement of the Chinese standard [20] (i.e., $N_{\mathrm{f}} \approx 10^{6.57} \approx 3.7 \times 10^{6}>2.0 \times 10^{6}$ ). However, considering the environmental effects, such as the corrosion of rebar/prestressed strand, especially taking into account the negative effects of the low quality of concrete casting, and so forth, the coupling of train loads and environmental effects generally highly reduces the fatigue life of the bridge compared with that only of train loading $[4,6,8,21]$ (see Figure 8(c)).

Furthermore, relating to performance deterioration, the conclusion is obtained from Figures 9(a)-9(c), 9(i), and 9(j) as follows. Firstly, the damage evolves linearly to $D \approx 0.4$ during the second stage (i.e., $10 \% N_{\mathrm{f}} \sim 80 \% N_{\mathrm{f}}$ ), when the coupling of stiffness degradation and inelastic deformation is taken into account. Secondly, the stiffness reduces slowly and linearly to $80 \%$ of the initial stiffness (according to the elastic damage variable $D_{\mathrm{E}} \approx 0.2$, see Figures $9(\mathrm{~b})$ and $9(\mathrm{j})$ ), and the residual midspan deflection reaches to $2.0 \mathrm{~mm}$ (relating to the inelastic damage variable $D_{\mathrm{i}} \approx 0.2$, see Figures 4 and $9(\mathrm{c})$ ), when the bridge is subjected to the train loading with a 30-ton axle weight. Thirdly, the ratio of the specimen maximum midspan deflection of $N \approx 3.0 \times 10^{6}$ to the initial maximum deflection is $150 \%\left(f_{\max }\right.$ is $12.0 \mathrm{~mm}$ and $8.0 \mathrm{~mm}$, resp.), and it is $250 \%$ to fatigue failure $\left(f_{\max }\right.$ is $20.0 \mathrm{~mm}$ and $8.0 \mathrm{~mm}$, resp.), when the bridge is subjected to the train loading with a 30-ton axle weight. Fourthly, by applying the mechanical similarity mentioned in the specimen design section, it is speculated that the residual midspan deflection for the bridge on site is $f_{\mathrm{r}} \approx 2.0 \times 6=12.0 \mathrm{~mm}$, when the bridge is subjected to the train loading with a 30 -ton axle weight experiencing cycle number $N \approx 3.0 \times 10^{6}$. Therefore, the performance deterioration of the bridge may cause serious traffic safety problems, especially considering the dynamic coupling of the train and the bridge [28, 29].

\section{Conclusions}

This work monitored the performance deterioration of the scale models of a typical heavy-haul railway bridge under fatigue loading, analyzed the results of the failure mode, the fatigue life, the loads-midspan deflection response and the materials strain development, and so forth, by using a multisensor system, and further developed the comprehensive $S-N$ model and the damage evolution model considering the coupling of stiffness degradation and inelastic deformation. The conclusions are able to be drawn as follows:

(1) By comparing the relationship between the fatigue life and the rebar stress range with that of the fatigue life and the load level, the $S-N$ model was developed in this work obtaining more comprehensive and accurate predictions. The fatigue life of the specimens is determined by the fatigue life of the rebar at the bottom. The fatigue life of the bridge subjected to the train loading with a 30-ton axle weight may be lower than $2.0 \times 10^{6}$ cycles when the environmental factors are taken into account. 
(2) The damage evolution model considered the coupling of the stiffness degradation and the inelastic deformation development is more reasonable than not. The predictions agree with the experimental results. The damage evolution obtained a threestage process with a constantly sloped linear developing during the second stage.

Therefore, this work furthers the understanding of the performance deterioration of the heavy-haul railway bridge under fatigue loading. And it may also be able to help maintain and monitor the other partially prestressed concrete beams.

\section{Conflicts of Interest}

The authors declare that they have no competing interests.

\section{Acknowledgments}

The studies presented here were developed within the research projects U1434204, 51378506, and 51278496 funded by the National Natural Science Foundation of China, whose assistance is gratefully acknowledged.

\section{References}

[1] W. Hou, "Construction of Datong-Qinhuangdao heavy-haul railway and operation management technique," China Railway Science, vol. 22, no. 6, pp. 135-136, 2001.

[2] J. Zuo, "Influence on the upper-structure of the existing bridges from the 20000-ton heavy-haul trains running in Datong-Qinhuangdao railway," Railway Standard Design, vol. 1, pp. 43-44, 2006.

[3] Z. Geng, Heavy-Haul Transportation Technologies on DatongQinhuangdao Railway, China Railway Publishing House, Beijing, 2009.

[4] J. Sun, Q. Huang, and Y. Ren, "Performance deterioration of corroded RC beams and reinforcing bars under repeated loading," Construction and Building Materials, vol. 96, pp. 404415, 2015.

[5] F. Liu and J. Zhou, "Fatigue strain and damage analysis of concrete in reinforced concrete beams under constant amplitude fatigue loading," Shock and Vibration, vol. 2016, Article ID 3950140, 7 pages, 2016.

[6] L. Song and Z. Yu, "Fatigue performance of corroded reinforced concrete beams strengthened with CFRP sheets," Construction and Building Materials, vol. 90, pp. 99-109, 2015.

[7] S. Parniani and H. Toutanji, "Monotonic and fatigue performance of RC beams strengthened with a polyurea coating system," Construction and Building Materials, vol. 101, pp. 22-29, 2015.

[8] W. Zhang, X. Liu, and X. Gu, "Fatigue behavior of corroded prestressed concrete beams," Construction and Building Materials, vol. 106, pp. 198-208, 2016.

[9] J. H. Xie, P. Y. Huang, and Y. C. Guo, "Fatigue behavior of reinforced concrete beams strengthened with prestressed fiber reinforced polymer," Construction and Building Materials, vol. 27, no. 1, pp. 149-157, 2012.

[10] X. Luo, Z. Yu, J. Nie, and X. Liu, "Experimental study on fatigue properties of self compacting prestreesed concrete beams," Journal of Building Structures, vol. 24, no. 3, pp. 7681, 2003.

[11] J. Han, Y. Song, and J. Chang, "Analysis model of crack width of partially prestressed concrete beams under fatigue loading," Journal of Central South University (Science and Technology), vol. 45, no. 11, pp. 3977-3985, 2014.

[12] M. H. Harajli, "Static and fatigue tests on partially prestressed beams," Journal of Structural Engineering, vol. 111, no. 7, pp. 1602-1618, 1985.

[13] M. El Shahawi, "Fatigue of partially prestressed concrete," Journal of Structural Engineering, vol. 112, no. 3, pp. 524537, 1986.

[14] A. E. Naaman and M. Founas, "Partially prestressed beams under random-amplitude fatigue loading," Journal of Structural Engineering, vol. 117, no. 12, pp. 3742-3761, 1991.

[15] Z. Yu, J. Li, and L. Song, "Experimental study on fatigue behaviors of heavy-haul railway bridges," China Civil Engineering Journal, vol. 45, no. 12, pp. 115-126, 2012.

[16] X. Luo and G. Dai, "Study on computational method of fatigue damages of unbonded prestressed high performance fly ash concrete bridges," Journal of the China Railway Society, vol. 31, no. 6, pp. 76-82, 2009.

[17] J. Li, Z. Yu, and L. Song, "Law of neutral axis variations of heavy-haul railway bridges under repeated fatigue loading," Journal of the China Railway Society, vol. 35, no. 6, pp. 96103, 2013

[18] General Administration of Quality Supervision and Inspection and Quarantine of the People's Republic of China, Metallic Materials-Tensile Testing at Ambient Temperature, Chinese Standard, Standards Press of China, Beijing, 2002.

[19] Ministry of Housing and Urban-Rural Development of the People's Republic of China, Standard for Test Method of Concrete Structures, Chinese Standard, China Architecture \& Building Press, Beijing, 1992.

[20] Ministry of Railways of the People's Republic of China, Code for Design on Reinforced and Prestressed Concrete Structure of Railway Bridge and Culvert, Chinese Standard, China Railway Press, Beijing, 2005.

[21] Z. Zeng and Z. Li, "Research on fatigue $S-N$ curves of reinforcing bars in common reinforced concrete beams," China Civil Engineering Journal, vol. 32, no. 5, pp. 10-14, 1999.

[22] Railway Technical Research Institute (RTRI), Design Code for Railway Structures and Its Explanation. Japanese Standard, 2000.

[23] C. Jiang, X. Gu, Q. Huang, and W. Zhang, "Deformation of concrete under high-cycle fatigue loads in uniaxial and eccentric compression," Construction and Building Materials, vol. 141, pp. 379-392, 2017.

[24] Z. Shan and Z. Yu, "A fiber bundle-plastic chain model for quasi-brittle materials under uniaxial loading," Journal of Statistical Mechanics: Theory and Experiment, article P11010, 2015.

[25] Z. Yu, Z. Shan, Z. Ouyang, and F. Guo, "A simple damage model for concrete considering irreversible mode-II microcracks," Fatigue \& Fracture of Engineering Materials \& Structure, vol. 39, no. 11, pp. 1419-1432, 2016.

[26] Z. Yu, S. Tan, Z. Shan, and X. Tian, "X-ray computed tomography quantification of damage in concrete under compression considering irreversible mode-II microcracks," Fatigue \& Fracture of Engineering Materials \& Structures, vol. 40, no. 12, pp. 1960-1972, 2017. 
[27] B. Qin, G. Sheng, and S. Gong, "Analysis on high strain low cycle fatigue properties of 20MnSiVHRB400 reinforced steel bars," Journal of Chongqing University, vol. 26, no. 7, pp. 9396, 2003.

[28] Z.-w. Yu, J.-f. Mao, F.-q. Guo, and W. Guo, "Non-stationary random vibration analysis of a $3 \mathrm{D}$ train-bridge system using the probability density evolution method," Journal of Sound and Vibration, vol. 366, pp. 173-189, 2016.

[29] J. Mao, Z. Yu, Y. Xiao, C. Jin, and Y. Bai, "Random dynamic analysis of a train-bridge coupled system involving random system parameters based on probability density evolution method," Probabilistic Engineering Mechanics, vol. 46, pp. 48-61, 2016. 


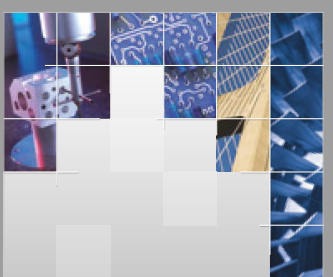

\section{Enfincering}
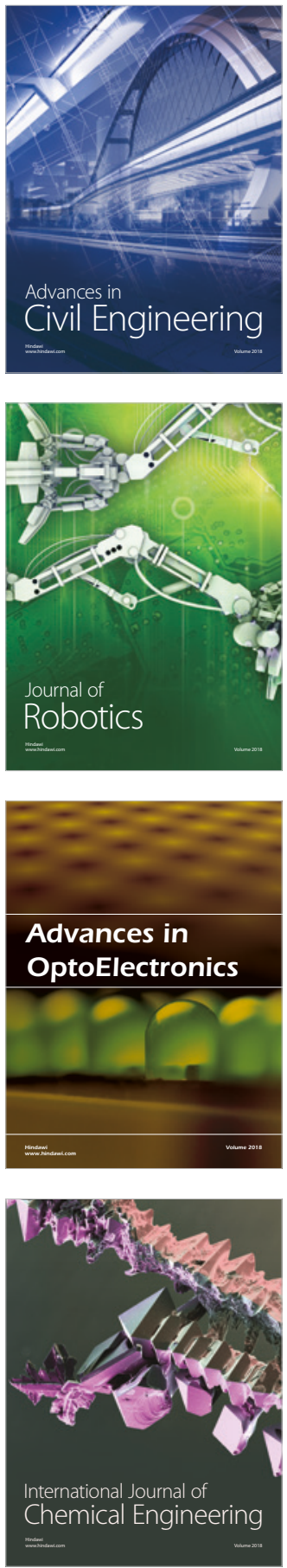

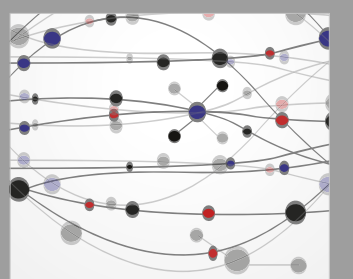

\section{Rotating \\ Machinery}

The Scientific World Journal

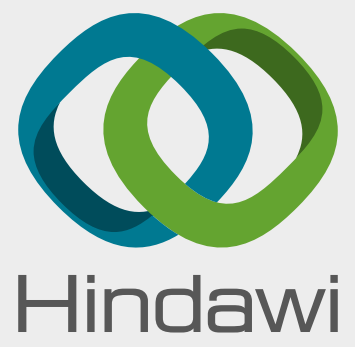

Submit your manuscripts at

www.hindawi.com
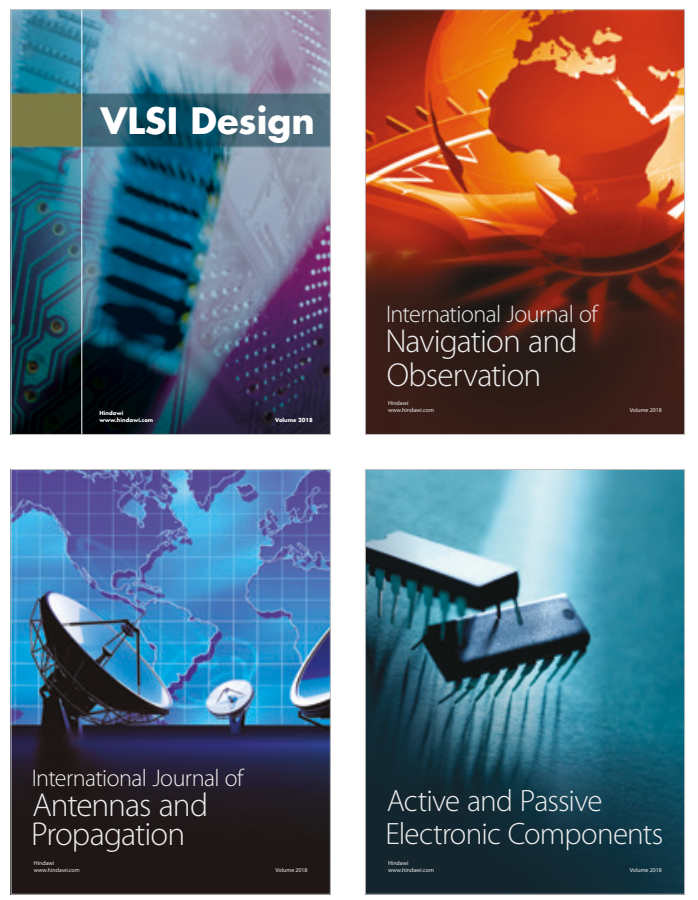
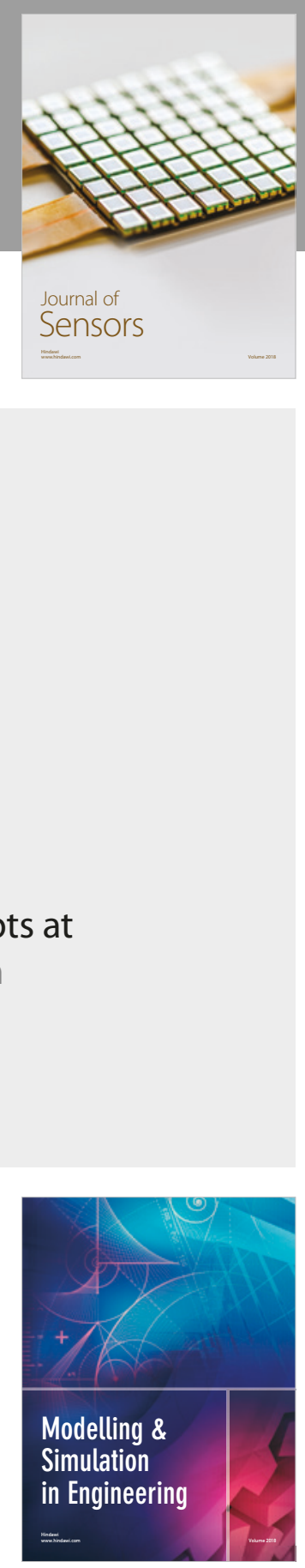

\section{Advances \\ Multimedia}
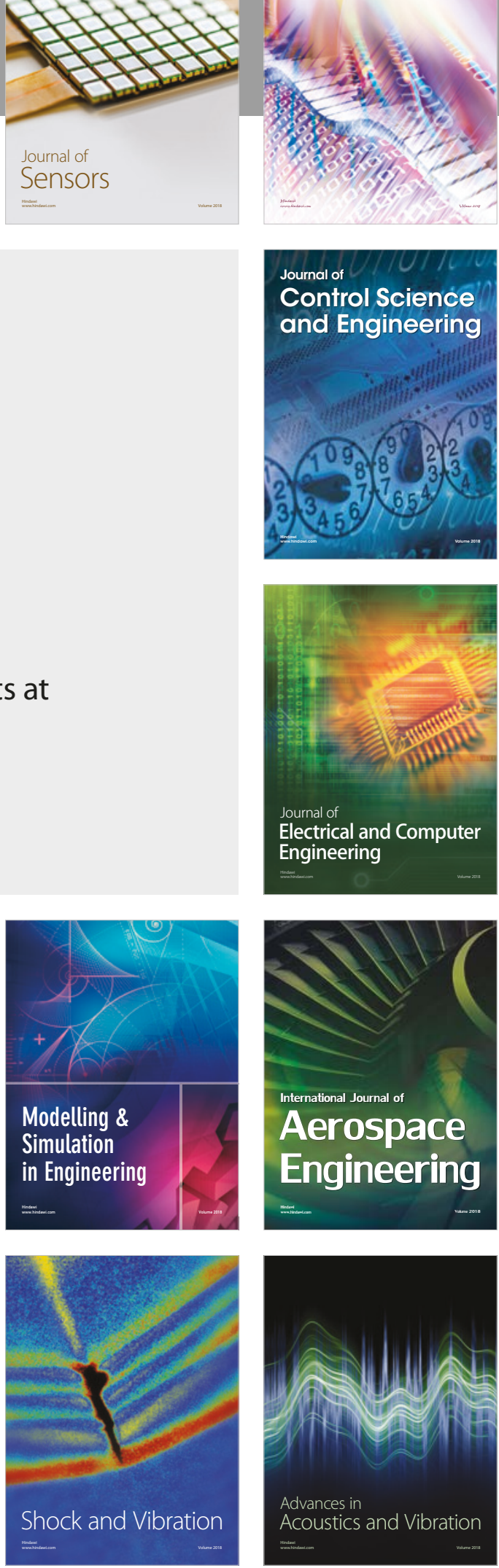